\title{
In-situ measurements of sorption parameters with a Field and Laboratory Emission Cell (FLEC): a comparison to the test emission chamber method
}

\author{
M. Rizk ${ }^{1,2}$, M. Verriele ${ }^{1}$, M. Mendez ${ }^{3}$, S. Dusanter ${ }^{1}$, \\ C. Schoemaecker ${ }^{4}$, S. Le Calvé ${ }^{2} \&$ N. Locoge ${ }^{1}$ \\ ${ }^{1}$ SAGE, Mines Douai, France \\ ${ }^{2} I C P E E S$, Strasbourg University \& CNRS, France \\ ${ }^{3}$ LIVE, Strasbourg University \& CNRS, France \\ ${ }^{4} P C 2 A$, Lille 1 University \& CNRS, France
}

\begin{abstract}
A new method has been developed to measure sorption parameters on indoor surfaces on the field, based on the coupling of a Field and Laboratory Emission Cell (FLEC) and a Proton Transfer Reaction - Mass Spectrometer (PTR-MS). In this work, the method used for field applications is compared to the conventional method (used for laboratory scale experiment only) based on a 50-liter glass chamber (CLIMPAQ) coupled to an on-line GC analyser. The sorption of ethyl benzene on an unpainted gypsum board (exposed to a BTEX mixture) is presented. The CLIMPAQ experiment takes 13 times (160 hours) more than a FLEC experiment (12 hours). In addition, the FLEC walls do not present any sorption effect on internal walls while the CLIMPAQ shows important sink effect that can reach $45 \pm 2 \%$ of the total amount of injected concentration. The sorption parameters $\mathrm{k}_{\mathrm{a}}$ and $\mathrm{k}_{\mathrm{d}}$ were derived from the experimental concentration profiles using Tichenor's model and taking into account the walls sink effect for the CLIMPAQ. While the analysis of the FLEC data is very responsive to sorption parameters variation, the CLIMPAQ one leads to a large range of solutions for the same experimental profile. Therefore, the FLEC method is useful to measure accurately and within few hours sorption parameters in real indoor environments. Keywords: emission test chamber, field and laboratory emission cell, sorption parameters, mathematical model.
\end{abstract}




\section{Introduction}

Nowadays, indoor air quality is becoming an important field of research since people spend between $60-80 \%$ of their time in indoor areas that can be contaminated by different type of pollutants having hazardous effects on human health especially Volatile Organic Compounds (VOCs) [1]. Other than their emissions by surfaces [2], VOCs can interact with indoor materials through different processes including adsorption and desorption that could have an impact on VOCs indoor air concentrations $[3,4]$.

New researches aims at modelling indoor air quality using different parameters such as air exchange rate, emission rates of VOCs and sorption parameters of VOCs on surfaces. However, indoor air quality models failed to predict real indoor concentrations [5] with a difference as high as a factor of 9 [6]. In fact, sorption rate coefficients of VOCs on indoor materials are not measured on the field but determined in emission test chambers on the laboratory scale. The missing data for real situations may be responsible of this discrepancy because the laboratory works can be not completely representative of field conditions (type of material, implementation conditions, aging due to environmental conditions, etc.). This finding highlights the need to reliably measure sorption parameters on the field under real conditions in order to find out the role of sinks for different VOC indoors. This measurement helps to quantify the contribution of sorption phenomena to the levels of VOC indoors, which are also affected by other processes like emissions, ventilation and reactivity phenomena.

Trying to fill this gap found in literature, we developed [7] a new method based on a coupling between a FLEC (Field and Laboratory Emission Cell) and a PTRMS (Proton Transfer Reaction - Mass Spectrometer), to measure VOC sorption parameters on the field within 0.5-12 hours compared to emission test chambers that require several days of measurements. Adsorption and desorption coefficient rates were derived using Tichenor model [4] that can be applied to the FLEC cavity to determine elementary sorption coefficients independently on flow conditions in the range recommended for the FLEC use $\left(<1000 \mathrm{ml} . \mathrm{min}^{-1}\right)$ and on VOC concentrations, with an experimental error less than $10 \%$. Nevertheless, a comparison of this novel method with the conventional emission test chamber method commonly used to measure sorption coefficients (lab-scale experiment only) is recommended.

The aim of the present study is then to compare FLEC-PTRMS device to the classical laboratory chamber CLIMPAQ (Chamber for Laboratory Investigations of Materials, Pollution and Air Quality) coupled to a gas chromatography analyser.

\section{Experimental procedure}

\subsection{Chemicals and test material}

A mixture of aromatic VOCs (benzene, toluene, ethylbenzene and o/p-xylène) provided by Air products was used. A $12.5 \mathrm{~mm}$ thick unpainted gypsum board was used for both experiments carried out using FLEC or CLIMPAQ. Before tests, the 
test pieces were wrapped in none emitting and airproof aluminium bags and stored at $4^{\circ} \mathrm{C}$ to be used few months later.

\subsection{Emission Chamber and sampling method}

An emission test chamber (CLIMPAQ) of 50.9 litres was used for the experiments [8]. One internal fan recirculates the air over the test material. The chamber outlet is connected to on-line gas chromatography (GC) with flame ionization detector (FID) (Airmo VOC C6C12, Chromatotec).

\subsection{Sorption experiments}

For the adsorption phase, the chamber or the FLEC is supplied with humidified and diluted air containing target VOCs using a gas cylinder connected to a dilution system (Gas Calibration Units, Ioniconanalytick) controlling the flow rate and the humidity. When monitored concentrations reach equilibrium, desorption phase is achieved by supplying the chamber or the FLEC with zero air at the same flow rate and humidity, using zero air generator and a water bubbler connected to mass flow controllers (MKS). A blank experiment referred in the following "No sink" is performed using an empty chamber to evaluate the sink effect of the setup itself. The experimental conditions used for the CLIMPAQ experiment are summarized in Table 1 with those used for FLEC experiments.

Table 1: Experimental conditions for CLIMPAQ and FLEC.

\begin{tabular}{lcc}
\hline Parameters & CLIMPAQ & FLEC \\
\hline Temperature $\left({ }^{\circ} \mathrm{C}\right)$ & \multicolumn{2}{c}{$23 \pm 2^{*}$} \\
Relative humidity $(\% \mathrm{RH})$ & $50 \pm 5^{*}$ \\
Volume $\left(\mathrm{V} ; \mathrm{m}^{-3}\right)$ & $50.9 \times 10^{-3}$ & $35 \times 10^{-6}$ \\
Air Flow $\left(\mathrm{F} ; \mathrm{ml} \mathrm{min}^{-1}\right)$ & $200^{*}$ & $300-500$ \\
Air exchange rate $\left(\mathrm{N} ; \mathrm{h}^{-1}\right)$ & $0.3^{*}( \pm 5 \%)$ & $514.3-857.1^{* *}$ \\
Air velocity at test material surface $\left(\mathrm{v} ; \mathrm{m} \mathrm{s}^{-1}\right)$ & $0.16^{*}$ & $0.0106-0.0177^{* *}$ \\
Area of test piece $\left(\mathrm{A} ; \mathrm{m}^{2}\right)$ & 0.099 & $0.0177^{* *}$ \\
Loading factor $\left(\mathrm{L} ; \mathrm{m}^{2} \mathrm{~m}^{-3}\right)$ & 1.94 & $505.7^{* *}$ \\
& Ethylbenzene & $\mathrm{C} 8$ aromatics \\
Concentration $\left(\mu \mathrm{g} \cdot \mathrm{m}^{-3}\right)$ & $127.6^{*}$ & $\mathbf{2 8 9 - 8 6 8}$ \\
& & \\
\hline
\end{tabular}

*Experimental conditions; ** $[4,9]$.

\section{Results}

\subsection{Sorption experiment}

The concentration profiles obtained with the CLIMPAQ experiment are compared with those obtained with the FLEC. Using the PTR-MS technique the C8- 
aromatics compounds are detected together as the sum of ethylbenzene and o$\mathrm{p} / \mathrm{xylene}$ measured at the same mass $(\mathrm{m} / \mathrm{z}=107)$, unlike the GC-FID technique allowing an individual detection of each compound.

The theoretical concentrations that should be obtained for a blank experiment when the CLIMPAQ or FLEC is empty (No sink), were also calculated [4] for the conditions of this study assuming negligible walls effects. The equation used is:

$$
C(t)=C_{e} e^{-N t}
$$

with $C(t)$ the concentration versus time $\left(\mu \mathrm{g} \cdot \mathrm{m}^{-3}\right) ; C_{e}$ the equilibrium concentration reached at the end of the adsorption phase $\left(\mu \mathrm{g} \cdot \mathrm{m}^{-3}\right)$ and $N$ the experimental air exchange rate experimentally measured $\left(\mathrm{h}^{-1}\right)$.
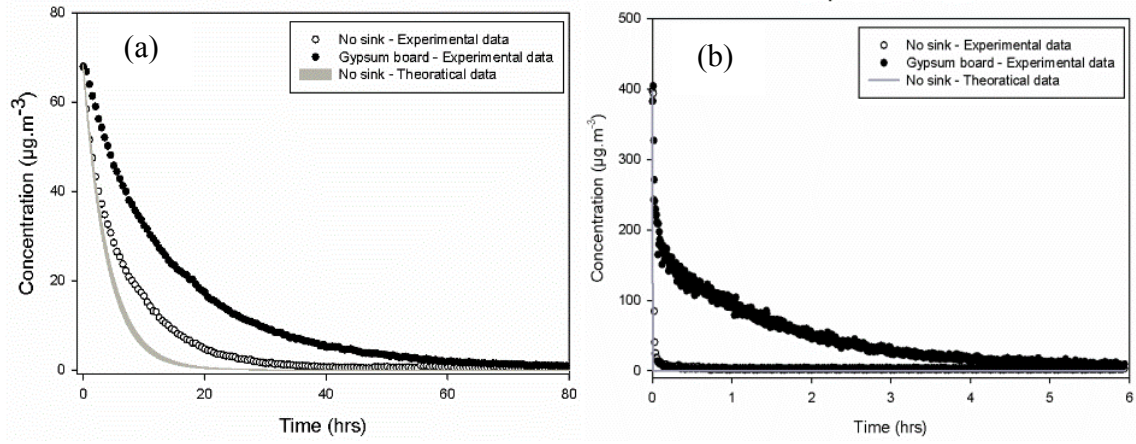

Figure 1: Concentration decay of ethylbenzene in CLIMPAQ (a) compared to C8 aromatics in FLEC (b).

The first point to note is that the CLIMPAQ desorption experiment takes more than 13 times ( 80 hours) to be achieved comparing to a FLEC experiment (6 hours). In addition, a sorption effect is detected on the internal walls of the CLIMPAQ chamber unlike the FLEC. In the CLIMPACQ case, the calculation of the difference between the theoretical and experimental profiles shows a net loss of $45 \pm 2 \%$ for the injected concentration of ethyl benzene. This phenomenon was reported in other studies [10-12] with approximately the same order of magnitude. As mentioned in these studies, there is yet any satisfactory explanation proposed to understand the cause justifying this loss but it is presumably not due to aeraulic heterogeneity of the chamber. This discrepancy shows that the chamber itself acts as a sink and that the chamber surface should be considered in the data analysis of the concentrations profiles obtained with the material.

\subsection{Determination of sorption parameters}

The sorption parameters were extracted using the Langmuir model (equation 2).

$$
\frac{d C_{g}}{d t}=N C_{i n}-N C_{g}-k_{a} C_{g} L+k_{d} C_{s} L
$$

where, $N$ is the air exchange rate $\left(\mathrm{h}^{-1}\right), C_{\text {in }}$ the VOC concentration at the chamber inlet $\left(\mu \mathrm{g} . \mathrm{m}^{-3}\right), C_{g}$ the gas-phase VOC concentration inside the chamber $\left(\mu \mathrm{g} \cdot \mathrm{m}^{-3}\right)$, 
$k_{a}$ the adsorption rate constant $\left(\mathrm{m} \cdot \mathrm{h}^{-1}\right), k_{d}$ the desorption rate constant $\left(\mathrm{h}^{-1}\right), C_{s}$ the surface concentration $\left(\mu \mathrm{g} \cdot \mathrm{m}^{-2}\right)$, and $L$ the loading factor $\left(\mathrm{m}^{2} \cdot \mathrm{m}^{-3}\right)$.

Firstly, the sorption parameters on CLIMPAQ walls (no sink parameters) were extracted using Langmuir model applied to one surface (Figure 2(a)). Secondly, the model was applied on two surfaces (i.e. the chamber walls and the gypsum board), to model the concentration profile obtained in the CLIMPAQ for the gypsum board experiment. For this, the sorption parameters for the gypsum board determined with FLEC method were used as inputs in combination with the no sink parameters of CLIMPAQ walls.
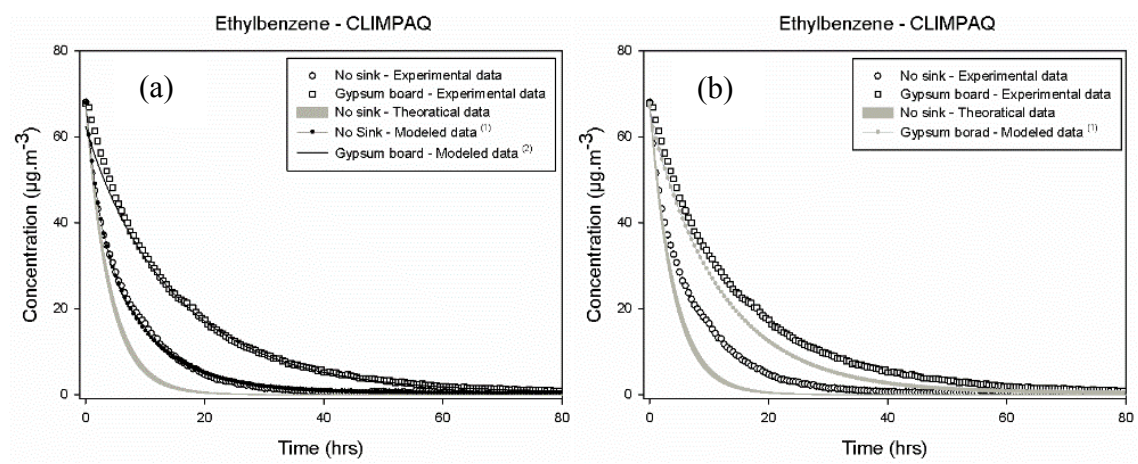

Figure 2: Analysis of the desorption phase using Langmuir model considering one surface (a) and considering two surfaces (b).

Using these data, the modelled profile obtained for the gypsum board, matches very well with the experimental data (Figure 2(a)). This result indicates that sorption parameters determined using FLEC method are consistent with those determined using CLIMPAQ method when the sink effect of CLIMPAQ walls is considered in the model.

To confirm the importance of the CLIMPAQ sink effect on the determination of the gypsum board sorption parameters, the same procedure was applied without taking into account the sorption effect on CLIMPAQ walls. Figure 2(b) shows that the obtained profile does not match with the experimental data.

\subsection{Robustness test}

An experiment was performed to test the robustness of the obtained solutions. For this, desorption curves in FLEC and CLIMPAQ were simulated using different couples of sorption parameters $\left(\mathrm{k}_{\mathrm{a}} ; \mathrm{k}_{\mathrm{d}}\right)$ but having the same ratio $\mathrm{K}_{\mathrm{e}}$ (corresponding to the experimental one). For example, random factors of 0.01 and 10 were used to multiply $\mathrm{k}_{\mathrm{a}}$ and $\mathrm{k}_{\mathrm{d}}$. Then curves were simulated using Langmuir model with $\left(\mathrm{k}_{\mathrm{a}} \times 0.1 ; \mathrm{k}_{\mathrm{d}} \times 0.1\right)$ and $\left(\mathrm{k}_{\mathrm{a}} \times 10 ; \mathrm{k}_{\mathrm{d}} \times 10\right)$.

For the CLIMPAQ case, the resulting modelled plots obtained for different couples of $k_{a}$ and $k_{d}$ with the same ratio $K_{e}$, presents similar profiles and a good match with experimental data. However, simulated curves obtained for the FLEC 
case are very different than the experimental data. This confirms the presence of unique solution for the experimental data obtained using FLEC method, which is very responsive to sorption parameters variation. Contrarily, the use of a large range of sorption parameters can retrieve the profile obtained in the CLIMPAQ showing that the determination of these parameters with this method is not accurate as the FLEC one and leads to a large range of solutions for the same experimental profile.
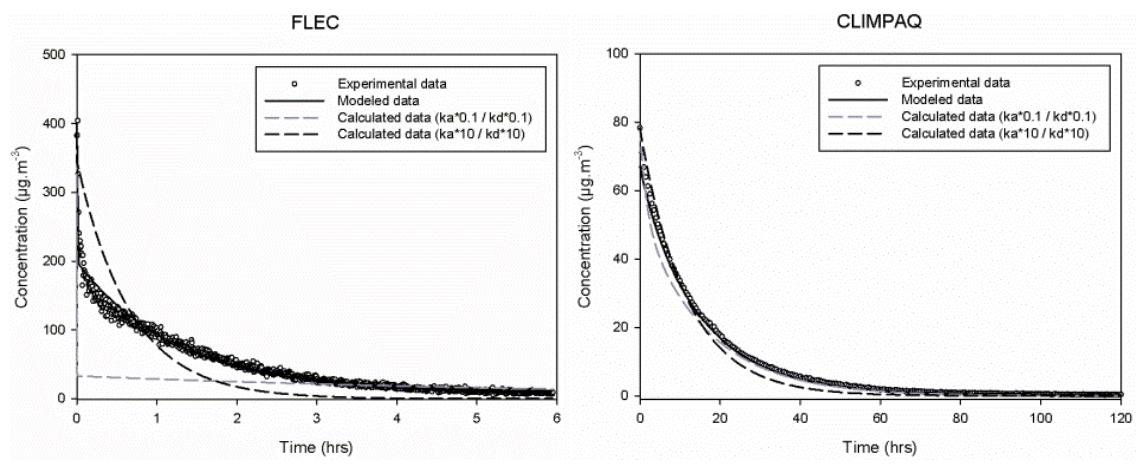

Figure 3: Comparison of modelled curves using different couples of $\mathrm{k}_{\mathrm{a}}$ and $\mathrm{k}_{\mathrm{d}}$ having the same ratio $\mathrm{K}_{\mathrm{e}}$.

\section{Conclusion}

Sorption experiment performed in an emission test chamber like CLIMPAQ presents many differences compared to that performed in FLEC in similar experimental conditions. While the FLEC presents any sorption phenomena on internal walls, the CLIMPAQ itself has an important sink effect that can reach $45 \%$ of the total amount of injected concentration. Therefore, chamber sink effect can introduce bias on derived parameters if this effect is not taken into account in the model used to derive sorption parameters. The analysis of the FLEC data was conducted using the simple model of Tichenor and the presence of unique solution for an experimental profile was approved. However, the CLIMPAQ data can present multiple solutions for the same experimental profile.

In actual applications, the FLEC method seems therefore to be very useful for field application or laboratory experiments even if this method require a fast analytical device such as the PTR-MS device. The measurement of sorption parameters of several VOCs on the surface of materials can be performed within few hours and can be derived accurately using Tichenor model.

\section{Acknowledgement}

This work was financially supported by the French Environment and Energy Management Agency ADEME (Agence De l'Environnmentet de la Maîtrise de l'Energie) through MERMAID project under PRIMEQUAL program. 


\section{References}

[1] Wolkoff, P. and G.D. Nielsen, Organic compounds in indoor air - their relevance for perceived indoor air quality? Atmospheric Environment, 2001. 35(26): pp. 4407-4417.

[2] Haghighat, F. and L. De Bellis, Material emission rates: Literature review, and the impact of indoor air temperature and relative humidity. Building and Environment, 1998. 33(5): pp. 261-277.

[3] Niedermayer, S., et al., VOC sorption and diffusion behavior of building materials. European Journal of Wood and Wood Products, 2013. 71(5): pp. 563-571.

[4] Tichenor, B.A., et al., The Interaction of Vapour Phase Organic Compounds with Indoor Sinks. Indoor air, 1991. 1(1): pp. 23-35.

[5] Sparks, L.E., et al., Volatile Organic Compound Emissions from Latex Paint - Part 2. Test House Studies and Indoor Air Quality (IAQ) Modeling, 1999, Munksgaard International Publishers. pp. 18-25.

[6] Won, D., et al., Validation of the surface sink model for sorptive interactions between VOCs and indoor materials. Atmospheric Environment, 2001. 35(26): pp. 4479-4488.

[7] Rizk M., et al., Sorption of Organic gases onto Building Materials: Development of a new device for In-situ Measurements. Indoor Air, Proceedings of the 13th International Conference on Indoor Air Quality and Climate, Hong Kong, 2014. 5: pp. 372-379.

[8] Gunnarsen, L., P.A. Nielsen, and P. Wolkoff, Design and Characterization of the CLIMPAQ, Chamber for Laboratory Investigations of Materials, Pollution and Air Quality*. Indoor Air, 1994. 4(1): pp. 56-62.

[9] ISO16000-10, Partie 10: Dosage de l'émission des composés organiques volatils de produits de construction et d'objets d'équipement - Méthode de la cellule d'essai d'émission (16000-10). 2006.

[10] De Bortoli, M. and A. Colombo, Determination of VOC emitted from indoor materials and products, interlaboratory comparison of small chamber measurments, 1993, ECA: Ispra Joint Research Center.

[11] Kirchner, S., et al., Characterization of adsorption/desorption of volatile organic compounds on indoor surface materials. Healthy Buildings 95, Proceedings of a conference held Milan, 1995: pp. 953-958.

[12] Sollinger, S., K. Levsen, and G. Wünsch, Indoor air pollution by organic emissions from textile floor coverings. Climate chamber studies under dynamic conditions. Atmospheric Environment. Part B. Urban Atmosphere, 1993. 27(2): pp. 183-192. 